\title{
Mapping the Impact of a Polar Aprotic Solvent on the Microstructure and Dynamic Phase Transition in Glycerol Monooleate/Oleic Acid Systems
}

\author{
Gliserol Monooleat/Oleik Asit Sistemlerinde Polar Aprotik Çözücünün \\ Mikroyapı ve Dinamik Faz Geçişine Etkisinin Haritalanması
}

\author{
(D) Marzuka Shoeb KAZI*, (D) Mohammed Hassan DEHGHAN \\ Y.B. Chavan College of Pharmacy, Department of Pharmaceutics, Dr. Rafiq Zakaria Campus, Aurangabad, India
}

\begin{abstract}
Objectives: The impact of incorporating a polar aprotic solvent, dimethyl sulfoxide (DMSO), in glycerol monooleate/oleic acid systems was evaluated briefly to map its influence on the gel microstructure and dynamic phase transition in controlling the performance of a polyene antifungal drug delivery system.

Materials and Methods: An in situ gelling fluid precursor system (IGFPS) exhibiting inverse lyotropic liquid crystalline phases was developed by simple solution add-mixture method. Polarized light microscopy, small angle X-ray scattering (SAXS), differential scanning calorimetry (DSC), and oscillatory rheological assessments were performed to ascertain microstructural modulations. The developed system was examined for minimum gelling volume, gelling time, swelling behavior, mucoadhesion, in vitro antifungal activity, and in vitro drug release.

Results: The SAXS study identifies the coexistence of Im3m cubic phase with HCP P63/mmc hexagonal structures. The SAXS and DSC data highlight DMSO's unique ability to work both as a kosmotropic or chaotropic solvent and to be a function of its concentration. The in vitro antifungal test results indicate the concentration of DMSO to be a controlling factor in drug release and diffusion. The in vitro drug release kinetic studies reveal that most of the gel samples follow the matrix model and anomalous type release as implied by Peppas model.

Conclusion: Finally, the antifungal IGFPS formulated was found to have the required low viscosity, responsive sol-gel phase transition, appreciative mechanical properties, and desirable antifungal effect with sustained drug release performance.
\end{abstract}

Key words: Dimethyl sulfoxide, glycerol monooleate, microstructure, oleic acid, small angle X-ray scattering

Öz

Amaç: Bir polien antifungal ilaç taşıyıcı sistem performansını kontrol etmek için polar aprotik çözücü olan dimetil sülfoksit'in (DMSO), gliserol monooleat/oleik asit sistemlerine dahil edilmesinin, jel mikroyapısı ve dinamik faz geçiși üzerindeki etkisi araștırılmıştır.

Gereç ve Yöntemler: Invers liyotropik sıvı kristalin (LLC) fazları sergileyen in situ jelleșen öncü sıvı sistemi (IGFPS), basit çözelti ilave etme yöntemi ile geliștirilmiştir. Polarize ıșık mikroskopisi (PLM), küçük açılı X-ışını saçılması (SAXS), diferansiyel tarama kalorimetrisi (DSC) ve reolojik osilatör ölçümleri mikroyapısal modifikasyonları belirlemek için yapılmıştır. Geliştirilen sistem, minimum jelleşme hacmi, jelleşme süresi, şişme davranışı, mukoyapışkanlık, in vitro antifungal aktivite ve in vitro ilaç salımı açısından incelenmiştir.

Bulgular: SAXS çalıșması, Im3m kübik fazın HCP P63/mmc altıgen yapılarla bir arada varlığını tanımlamıștır. SAXS ve DSC verileri, DMSO'nun hem bir kozmotropik hem de kaotropik çözücü olarak görev yaptığını ve işlevini konsantrasyon bağımlığı olarak gerçekleştirdiğini gösterdiğinden DMSO'nun eşsiz yeteneğini vurgulamıştır. In vitro antifungal test sonuçları, DMSO konsantrasyonunun ilaç salımı ve difüzyonunda kontrol edici bir faktör olduğunu göstermiştir. In vitro ilaç salım kinetik çalışmaları, jel örneklerinin çoğunun matris modeli ve Peppas modelinin belirttiği gibi anormal tip salım kinetiğini takip ettiğini ortaya koymuștur.

Sonuç: Sonuç olarak, formüle edilen antifungal IGFPS'nin, gerekli düşük viskoziteye, duyarlı sol-jel faz geçişine, istenen mekanik özelliklere ve sürekli ilaç salım performansı ile arzu edilen antifungal etkiye sahip olduğu bulunmuştur.

Anahtar kelimeler: Dimetil sülfoksit, gliserol monooleat, mikroyapı, oleik asit, küçük açılı X-ışını saçılması

*Correspondence: E-mail: marzi345@gmail.com, Phone: +919975145944 ORCID-ID: orcid.org/0000-0002-6103-7806

Received: 04.06.2019, Accepted: 03.08.2019

-Turk J Pharm Sci, Published by Galenos Publishing House. 


\section{INTRODUCTION}

Dimethyl sulfoxide [(DMSO, $\left.\left(\mathrm{CH}_{3}\right)_{2} \mathrm{SO}\right)$ ] is a short amphiphilic moiety, conventionally used as a cryoprotectant and solvent for lipophilic drugs, and it is the solvent of choice for the synthesis of sugar ester (used for ice cream production), cell fusogen, and chemical penetration enhancer to deliver active molecules through the skin and into the cell.1.2 DMSO interacts with lipids to replace water in the inner region of lipid head groups, increasing the area of lipid and decreasing its thickness. ${ }^{3}$ The hydrophilic group of DMSO interrelates with water and polar head groups of lipids, whereas the two hydrophobic methyl groups intermingle with the hydrophobic inner membrane region of lipids. ${ }^{4}$ Due to its dual character, DMSO occupies the inner interface region and acts as a surfactant to stabilize the presence of water molecules. Lipids such as oleic acid (OA) and glycerol monooleate (GMO) have a polar head and a relatively short hydrophobic carbon chain. GMO is categorized as a GRAS approved nontoxic, biodegradable, and biocompatible material and is also cited in the Food and Drug Administration Inactive Ingredients Guide. GMO was introduced for the first time in 1930, for margarine production; since then it has been extensively used in the food industry as an emulsifier and stabilizer for foams in bread, cakes, margarine, ice cream, and chewing gum. ${ }^{5} \mathrm{OA}$ is a monounsaturated fatty acid (triglyceride) component of the human diet obtained from animal fats and vegetable oils.

The interaction of DMSO with OA and GMO results in modulation of the microstructure of the lyotropic liquid crystalline (LLC) system, which is formed due to transformation of the sol system to the gel phase upon contact with external stimuli like body fluids and excess water. The microstructure formed is primarily controlled by additives in the system and the nature of the drug, i.e. hydrophilic or lipophilic. The reversed hexagonal and bicontinuous cubic mesophases are spontaneously formed from the in situ gelling liquid crystal forming system with impetus to an external stimulus. The tortuous networks of aqueous nanochannels formed in these mesophases partake as gateways for the sustained release of drugs from the gelled liquid crystal structure. In the present investigation, an in situ gelling system was developed by adding a polyene antifungal agent, nystatin, widely used against susceptible cutaneous and mucocutaneous fungal infections caused by Candida species and exhibiting a broad spectrum of activity against other fungi such as Aspergillus and Cryptococcus. Interestingly, there are reports that this polyene moiety interacts with phospholipids and therefore liposomal formulations have been developed to reduce its toxic effects. ${ }^{6}$

In the present study, the impact of incorporating a polar aprotic solvent, DMSO, in a GMO/OA system was evaluated briefly to map its influence on the gel microstructure and dynamic phase transition in controlling the performance of a polyene antifungal drug delivery system.

\section{MATERIALS AND METHODS}

\section{Materials}

Nystatin was procured as a gift sample from Glenmark Pharmaceuticals, Mumbai. Cithrol GMO-HP-SO-LK was a gift sample obtained from Croda. OA, DMSO, methanol, dimethyl formamide, and chloroform were acquired from Loba Chemie, Mumbai. Dextrose, peptone, and agar were purchased from Fisher Scientific, India. Aspergillus fumigatus (NCIM 902) and Candida albicans (ATCC 18804) were procured from the National Chemical Laboratory, Pune. Cellulose acetate membrane pore size $0.45 \mu \mathrm{m}$ was purchased from Millipore. Goat intestinal mucosa was obtained from a local slaughterhouse.

Formulation of in situ gelling fluid precursor systems (IGFPS) The formulation of IGFPS is summarized in Table 1. To prepare it by simple add-mixture method, briefly nystatin $(2.23 \% \mathrm{w} / \mathrm{w})$ was dissolved in DMSO; the resulting solution was added to $\mathrm{OA}$ and vortex mixed (B-6R-47, Biocraft Scientific Systems) for $5 \mathrm{~min}$ to obtain a homogeneous solution. The resulting solution was then added to melted $\left(40 \pm 2{ }^{\circ} \mathrm{C}\right) \mathrm{GMO}$ and vortex mixed for an additional $15 \mathrm{~min}$. The IGFPS were stored at room temperature until further characterization was performed.

\section{Characterization}

\section{In situ gelling ability and gelation time}

The minimum solvent $(\mathrm{Vm})$ and minimum time $(\mathrm{Tm})$ required for complete gelation of IGFPS was determined by magnetic stirring method. ${ }^{7}$ First $1 \mathrm{~g}$ of the IGFPS was aliquoted into a 5 $\mathrm{mL}$ vial and then a magnetic bar $(10 \mathrm{~mm} \times 6 \mathrm{~mm})$ was added to the vial. The temperature was maintained at $37.0 \pm 0.5^{\circ} \mathrm{C}$ and the speed of the magnetic bar was set at $30 \mathrm{rpm}$. Distilled water (10 $\mu \mathrm{L}$ ) was added to the vial each minute, until the magnetic bar completely stopped moving due to gelation. For Tm the above procedure was used and an excess amount of distilled water was added to the vial; the time required for complete halt of magnetic bar was noted as Tm.

\begin{tabular}{ll} 
Table 1. Formulation of IGFPS & \\
Formulation & Oleic acid:DMSO $(\% \mathrm{w} / \mathrm{w})$ \\
\hline F1 & $1: 3$ \\
\hline F2 & $1: 5$ \\
\hline F3 & $1: 4$ \\
\hline F4 & $3: 4$ \\
\hline F5 & $1: 1$ \\
\hline F6 & $3: 5$ \\
\hline F7 & $2: 3$ \\
\hline F8 & $2: 5$ \\
\hline F9 & $1: 2$ \\
\hline
\end{tabular}

*GMO was added quantity sufficient to $100 \% \mathrm{w} / \mathrm{w}$ GMO: Glycerol monooleate, IGFPS: In situ gelling fluid precursor systems, DMSO: Dimethyl sulfoxide 


\section{Drug content and $p H$ value of IGFPS}

For drug content determination, briefly $1 \mathrm{~g}$ of formed gel was dissolved in $100 \mathrm{~mL}$ of solvent system comprising methanol:dimethylformamide (DMF):water (55:15:30) and was evaluated at $306 \mathrm{~nm}$ using a Shimadzu ultraviolet (UV)-1600 spectrophotometer. The $\mathrm{pH}$ value of IGFPS was determined using a Systronics Digital pH meter 335.

\section{Swelling studies}

The water uptake of the systems was measured gravimetrically at fixed time intervals. Briefly $0.5 \mathrm{~g}$ of IGFPS was weighed on filter paper ( $40 \mathrm{~mm}$ in diameter) soaked in distilled water and positioned on top of a sponge $(5 \mathrm{~cm} \times 5 \mathrm{~cm} \times 2 \mathrm{~cm})$ previously soaked in the hydration medium and placed in a petri dish filled with distilled water to a height of $0.5 \mathrm{~cm} .{ }^{8}$ This investigational set-up was kept closed. The water uptake was determined as the increase in the weight of the sample over time normalized to the initial weight of the dry systems. ${ }^{8}$ The data were subjected to mathematical models ${ }^{9}$ using the following equations to affirm whether the kinetics of swelling was first order or second order.

$$
\ln \frac{w_{\infty}}{w_{\infty}-w}=k t \quad 1 \quad \frac{t}{w}=\frac{1}{k w_{\infty}^{2}}+\frac{t}{w} \quad 2
$$

where $W_{\infty}$ - maximum water uptake, $W$ - water uptake at time $t,\left(W_{\infty}-W\right)$ represents the unrealized water uptake, and $k$ is the proportionality constant. For second order kinetics, the initial rate of swelling is the reciprocal of the $y$-intercept in the plot of $t / W$ versus $t$. The reciprocal of the slope indicates $W_{\infty}$, which is the maximum or equilibrium water uptake. The units of $W_{\infty}$ are grams of buffer absorbed per gram of matrix $(\mathrm{g} / \mathrm{g})$, and the units of the initial swelling rate are grams of buffer absorbed per gram of dry matrix per hour $(\mathrm{g} / \mathrm{g} \mathrm{h}) .^{10,11}$

\section{Polarized light microscopy (PLM)}

The hydrated gels were evaluated at $20 \pm 0.5{ }^{\circ} \mathrm{C}, 27 \pm 0.5{ }^{\circ} \mathrm{C}$, and $37 \pm 0.5^{\circ} \mathrm{C}$ using microscopy (Carl Zeiss Jena, Germany) images under 40x magnifications. The samples were inserted between two glass microscope slides and observed with cross polarizers to ascertain the type of lyotropic liquid crystal mesophase formed on the basis of characteristic textures. ${ }^{12}$

\section{Mucoadhesion measurement by tensile strength method}

A CT3 Texture Analyzer (Brookfield Engineering, UK) was used for the tensile strength measurements. Fresh goat intestinal mucosa was obtained from a local slaughterhouse. The dissected mucosal pieces were kept in saline solution in an ice bath until the tests were performed. The mucosa was fastened to a $10 \mathrm{~mm}$ analytical movable probe of the texture analyzer by a rubber ring and the formulation was located on the lower platform. The system was maintained at $37 \pm 1^{\circ} \mathrm{C}$ by a thermostatic bath. The measurement was triggered to begin as the upper probe encountered a force of $3 \mathrm{mN}$ upon contact with the sample $(1 \mathrm{~g})$. The probe was kept in contact with no force applied for $60 \mathrm{~s}$, after which it was raised at a speed of $1 \mathrm{~mm} / \mathrm{s}$, and the force needed for detachment was estimated. The tensile work, which is proportional to the area under the force-time curve, was used to describe the mucoadhesive characteristics.

\section{Rheological measurements}

Rotational and oscillatory rheological tests were performed for formed gel samples using a Kinexus Rheometer (Malveran Instruments Ltd, UK). Rotational and oscillatory tests were performed at $37.0 \pm 0.1{ }^{\circ} \mathrm{C}$. Rotational tests were used to determine the viscosity and the data were analyzed for type of flow pattern. Oscillatory tests were performed to define the elastic modulus, loss modulus, and complex viscosity. The shear rate during the rotational tests ranged from 2 to 100 $\mathrm{s}^{-1}$. For oscillatory analysis, first stress sweep measurements (0.001-10\%) were performed at a constant frequency of $1 \mathrm{~Hz}$ in order to determine the linear viscoelastic region. Afterwards, oscillatory shear measurements were carried out as a function of frequency $(0.1-100 \mathrm{~Hz})$ at a constant strain of $0.1 \%$.

\section{Small angle $X$-ray scattering (SAXS)}

Scattering data were obtained by using a NANO-Viewer (Rigaku, Japan) with a 2D hybrid pixel array detector; $\mathrm{Cu} K \alpha$ was used as the radiation source $(0.154 \AA$ ) from the micro-focus rotating anode X-ray generator operated at a power rating of $40 \mathrm{kV}$ and $30 \mathrm{~mA}$. Samples were subjected to $X$-ray exposure for 10 min with the sample to detector distance set at $800 \mathrm{~mm}$. The measurements were performed at various temperatures, i.e. 20 ${ }^{\circ} \mathrm{C}, 27^{\circ} \mathrm{C}$, and $37^{\circ} \mathrm{C}$ with a q range of 0.028 to $0.213 \AA^{-1}$.

\section{Differential scanning calorimeter (DSC)}

A DSC Q 20 (TA Instruments) was used for analyzing the prepared samples. Indium and zinc standards were used for calibration of the instrument. First $10 \pm 3 \mathrm{mg}$ of hydrated sample was placed in aluminum crucibles separately. Then the crucibles were equilibrated at $25^{\circ} \mathrm{C}$ and the samples were rapidly cooled in liquid nitrogen from $25^{\circ} \mathrm{C}$ to $-25^{\circ} \mathrm{C}$, at a rate of $10{ }^{\circ} \mathrm{C} \mathrm{min}{ }^{-1}$. The samples were held at this temperature for $30 \mathrm{~min}$ and then were heated at a rate of $2{ }^{\circ} \mathrm{C} \mathrm{min}^{-1}$ to $50{ }^{\circ} \mathrm{C}$. An empty pan was used as reference. The fusion temperatures of the components and the total heat transferred in the thermal processes were determined.

\section{In vitro antifungal activity}

The in vitro antifungal activity of the formed gel was evaluated against Aspergillus fumigatus (NCIM 902) and Candida albicans (ATCC 18804). Briefly culture suspension of Candida albicans was prepared from fresh cultures (2 days old) grown on Sabouraud dextrose agar (SDA) slants, by dispersing one loopful of culture in $5 \mathrm{~mL}$ of sterile water and vortex mixing for $15 \mathrm{~s}$ to obtain a homogeneous suspension. The optical density of the resulting culture was determined by Elico spectro colorimeter $\mathrm{CL} 153$ set at value 1 at $600 \mathrm{~nm}^{13}$ Inoculum suspensions of Aspergillus fumigatus were prepared from fresh, mature (3-5 day old) cultures grown on SDA slants. The colonies were covered with $5 \mathrm{~mL}$ of distilled sterile water. Tween $20(1 \%)$ was added to facilitate the preparation of Aspergillus inocula..$^{14}$ The inocula were achieved by carefully rubbing the colonies with a sterile loop; the isolates were then shaken vigorously for 15 $\mathrm{s}$ with a vortex mixer and then transferred to a sterile tube. ${ }^{14}$ 
The optical density of the suspensions was measured by UV spectrophotometer (Shimadzu UV-1600) set as 0.13 at $530 \mathrm{~nm} .^{14}$ Agar well diffusion was used to evaluate antifungal activity; 1 $\mathrm{mL}$ of microbial inoculum was seeded into SDA medium and poured into petri plates, a sterile cork borer of diameter $6 \mathrm{~mm}$ was punched aseptically to create a well, and a gel sample (0.1 g) was added to the well. The plates were incubated for $24 \mathrm{~h}$ at 27 ${ }^{\circ} \mathrm{C}$ (Candida albicans) and $48 \mathrm{~h}$ at $27{ }^{\circ} \mathrm{C}$ (Aspergillus fumigatus). The drug released from the prepared gel was compared with standard drug solution of nystatin prepared in DMF (1000 units/ $\mathrm{mL}$ ). The antimicrobial agent diffuses in the agar medium and inhibits the growth of the microbial strain tested.

\section{In vitro drug release}

In vitro drug release was evaluated by placing cellulose acetate membrane $(0.45 \mu \mathrm{m})$ between the donor and the receptor chambers of a Franz diffusion cell. Briefly $1 \mathrm{~g}$ of prepared gel was placed on the membrane, the receptor compartment was filled with $50 \mathrm{~mL}$ of methanol:DMF:water (55:15:30) as the dissolution medium, ${ }^{15}$ and at fixed time interval $1 \mathrm{~mL}$ of the sample was withdrawn and replaced by fresh solvent to maintain sink condition. The temperature was maintained at 37 ${ }^{\circ} \mathrm{C}$ by circulating water bath. UV spectrophotometric analyses of aliquots were performed at $306 \mathrm{~nm}$ to estimate drug release. The experimental data obtained from the drug release experiments were evaluated for drug release kinetics, and PCPDisso-V 2.08 software was used to fit models to the release data. The models were assessed on the basis of correlation coefficient $\left(R^{2}\right)$ to mark the best fit model.

\section{Statistical analysis}

The data were articulated as mean \pm SD. ANOVA followed by post hoc Tukey test (GraphPad Prism 8.0.1) was employed to statistically analyze the data at $95 \%$ confidence level.

\section{RESULTS AND DISCUSSION}

\section{In situ gelling ability ( Vm) and gelling time (Tm)}

The additives added induce a change in the hydration state of the polar lipid head and affect the critical packing parameter (CPP) of the lipid. ${ }^{16-19}$ The effect of solvent on the gelling property of IGFPS is given in Table 2. It is observed that increasing the concentrations of DMSO and OA had a significant effect on the minimum amount of distilled water required for in situ gelling. A large amount of distilled water was required for gelling in the case of IGFPS of F2, whereas the smallest amount of solvent was required in $\mathrm{F} 5$. A higher concentration of DMSO results in disruption of water channels. ${ }^{20-22}$ In the case of F5 equal proportions of OA and DMSO cause the solvent to partition between both phases, i.e. the lipids and DMSO, thus making the polar heads of lipids easily available for hydration. Table 2 indicates the results obtained for Tm. It was found that there was a reverse relationship between the concentration of DMSO and the time required for gelling. The Tm was obtained in the following order for formulations containing higher DMSO content: F2>F3>F1>F8 $>F 6$, whereas an increase in OA concentration showed a reduction in gelation time F5<F4<F7<F9. Statistical analysis done using ANOVA followed by post hoc Tukey test for Tm reveal that comparing means of each group with the other showed a highly significant difference ( $p<0.05$, <0.0001), whereas an insignificant difference was seen in the case of F4 vs F5 ( $p>0.05,0.1043$ ) and F6 vs F9 ( $p>0.05$, $0.9762)$. In the case of $\mathrm{Vm}$, an insignificant difference was seen for $F 7$ vs $F 9$ ( $p>0.05,0.2233$ ), F4 vs F7 ( $p>0.05,0.6063), F 4$ vs F9 ( $p>0.05,0.9970), F 3$ vs F8 ( $p>0.05,0.9717$ ), and F1 vs F6 ( $p>0.05,0.999)$, while the other groups showed a significant difference ( $p<0.05,<0.0001)$.

\section{$\mathrm{pH}$ of the sol and drug content}

$\mathrm{pH}$ values of the sol and drug content are presented in Table 2. Almost all formulations showed a drug content in the range $99 \%$ to $100 \%$, while the $\mathrm{pH}$ of the sol for all formulations ranged from $5.5 \pm 0.11$ to $7 \pm 0.34$.

\section{Swelling studies}

The concentration of DMSO in IGFPS played an important role in modulating the microstructure of the formed gel and had a marked effect on rate of swelling. Figures 1a-1c highlight the swelling behavior: it was monitored for $8 \mathrm{~h}$. IGFPS formulations

Table 2. Minimum volume of solvent for gelation, gelation time and $\mathrm{pH}$

\begin{tabular}{llllll} 
Formulation & $\mathrm{Vm}(\mu \mathrm{L})$ & Water $(\% \mathrm{w} / \mathrm{w})$ & $\mathrm{Tm}(\mathrm{s})$ & $\mathrm{pH}$ & Drug content $(\%)$ \\
\hline $\mathrm{F} 1$ & $120 \pm 2.51$ & $10.86 \pm 0.75$ & $145 \pm 5$ & $6.2 \pm 0.21$ & $98.72 \pm 0.05$ \\
\hline $\mathrm{F} 2$ & $180 \pm 1.81$ & $15.51 \pm 1.15$ & $180 \pm 2.88$ & $7 \pm 0.34$ & $99.10 \pm 0.01$ \\
\hline $\mathrm{F} 3$ & $150 \pm 2.88$ & $13.15 \pm 0.95$ & $165 \pm 3$ & $6.6 \pm 0.12$ & $98.55 \pm 0.02$ \\
\hline F4 & $90 \pm 2.51$ & $8.33 \pm 0.5$ & $75 \pm 5$ & $6.3 \pm 0.15$ & $99.05 \pm 0.07$ \\
\hline F5 & $70 \pm 2$ & $6.66 \pm 0.4$ & $60 \pm 4$ & $5.5 \pm 0.11$ & $98.82 \pm 0.03$ \\
\hline F6 & $120 \pm 4.04$ & $10.9 \pm 0.8$ & $105 \pm 2.88$ & $6.7 \pm 0.09$ & $99.32 \pm 0.01$ \\
\hline F7 & $90 \pm 5.77$ & $8.4 \pm 0.6$ & $90 \pm 5$ & $5.8 \pm 0.17$ & $99.5 \pm 0.015$ \\
\hline F8 & $150 \pm 5$ & $13.15 \pm 1.02$ & $120 \pm 5$ & $6.8 \pm 0.12$ & $98.67 \pm 0.04$ \\
\hline F9 & $100 \pm 5.17$ & $9.25 \pm 0.75$ & $100 \pm 1.88$ & $6.4 \pm 0.13$ & $99.18 \pm 0.025$ \\
\hline
\end{tabular}

(Mean \pm standard deviation, $\mathrm{n}=3$ ), Vm: Minimum solvent, Tm: Minimum time 
with higher concentration of DMSO had higher rates of swelling, whereas formulations with higher concentration of OA had lower rates of swelling. It was markedly observed that formulations F7 and F5 in the initial hour showed faster rates of swelling (Figure 1b), but the same declined later and at the end of $8 \mathrm{~h}$ the maximum swelling observed was $24 \%$ and $22.75 \%$, respectively, and it was found to be dependent on water uptake. ${ }^{10}$ The rapid swelling is consistent with other studies signifying that formation of a viscous cubic or inverted hexagonal phase (HCP) is a fast process. ${ }^{23-25}$ IGFPS F2 exhibited the highest rate of swelling, i.e. $47 \%$ at $8 \mathrm{~h}$. Herein the concentration of DMSO, a polar additive, was higher, which preferentially led to the formation of a lamellar phase; thus DMSO had an opposite effect, as compared to OA, which could also be a reason for the higher rate of swelling. Moreover, the interaction of GMO with $\mathrm{OA}$ and subsequent hydration with water results in reversed hexagonal phases, whereas the interaction of DMSO with a high concentration of hydrated GMO results in predominant cubic phase existence. ${ }^{26,27}$ The results for minimum gelation volume are also along the same lines and demonstrate that concentration of DMSO has a significant effect on gelling as seen for swelling ability. The results of the statistical analysis show that an insignificant difference was noted $(p>0.05)$ on comparing the mean of each group with another; however, a significant difference was seen $(p<0.05,<0.01)$ for $F 2$ vs $F 4$, F2 vs F5, F2 vs F7, and F2 vs F9. Figure 1c indicates that all formulations followed second order swelling kinetics, which is in agreement with earlier reported studies. ${ }^{11,25,26}$

\section{Polarized light microscopy}

IGFPS undergo dynamic structural transition in situ to highviscous gel on exposure to excess water. This change from a less viscous system into a lamellar, bicontinuous cubic structure or inverted HCP can be elucidated by the CPP. 28,29 Figure 2 indicates PLM images at $20{ }^{\circ} \mathrm{C}$; all gel formulations except F2 exhibited a dark background with no birefringence characteristic of isotropic liquid crystalline

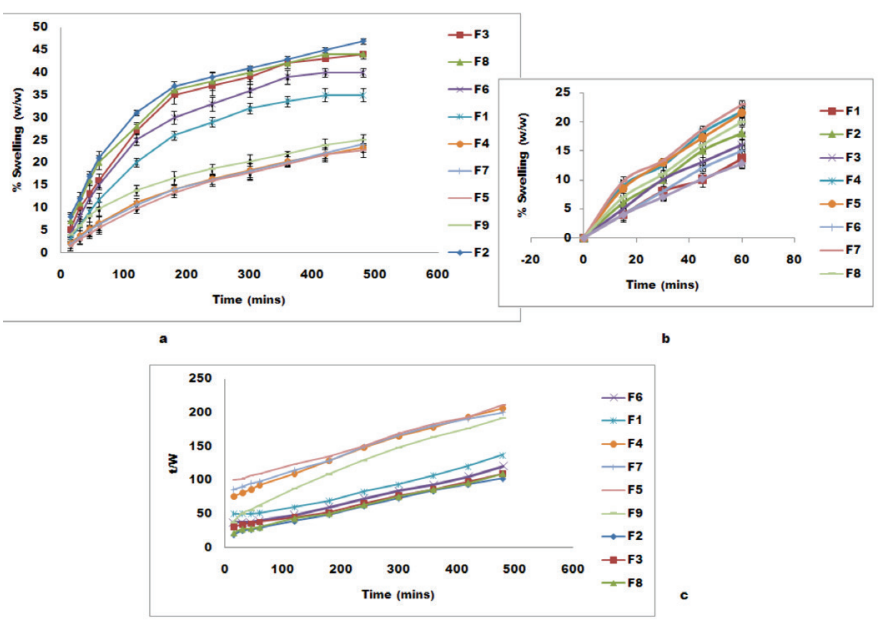

Figure 1. (a) Plots of the percentage increase in the weight as a function of time when placed in excess of water, (b) plots of percentage increase in weight in the initial hour when placed in excess of water, (c) plots of swelling kinetics of different formulation according to second order kinetics mesophase structure and very possibly a mesomorphic form of bicontinuous cubic structure, whereas F2 gels cast a two phase region of lamellar reflects presenting partial textures of birefringence pattern typical of a Maltese cross and black background of a cubic phase. PLM images obtained at $25{ }^{\circ} \mathrm{C}$ and $37{ }^{\circ} \mathrm{C}$ (Figure 2) exhibit typical dark backgrounds for $\mathrm{F} 1$ and F6 highlighting a cubic phase, whereas F2 typically shows only a Maltese cross pattern, thus indicating complete phase transformation to a lamellar structure. For the rest of the gel formulations, the coexistence of a two phase region with the formation of anisotropic structures with specific fan-like texture was distinctive of a reverse hexagonal structure on an isotropic black background featuring a cubic phase.

\section{Mucoadhesion measurement by tensile strength method}

The mucoadhesive properties of LLC systems are seen to be dependent on the dehydration of the mucosa and in situ absorption of water. Intestinal mucosa was selected as a model tissue to understand the influence of formulation additives and mesophase formation on mucodhesion. Table 3 highlights the results for mechanical parameters and bioadhesive force of the gel. The findings indicate that formulation F7 had the highest hardness $(1274 \pm 60 \mathrm{mN})$, compressibility $(1.612 \pm 0.072$ $\mathrm{mJ})$, adhesiveness $(3.143 \pm 0.12 \mathrm{~mJ})$, cohesiveness (1.961 \pm 0.053$)$, and bioadhesion force $(1010.08 \pm 50 \mathrm{mN})$. On comparing the mean values between formulation F5, F7, and F4 a significant difference ( $p<0.05)$ was noted for the mentioned parameters. The findings indicate that increasing concentration of OA imparted a better adhesiveness and gel strength for F7, whereas the adhesive force of the gels decreased as the OA content increased as seen for formulations F4 and F5. As the compactness of the microstructure increases with an increase in OA concentration, the lattice parameter value decreases with narrowing of the water channels, leading to a decline
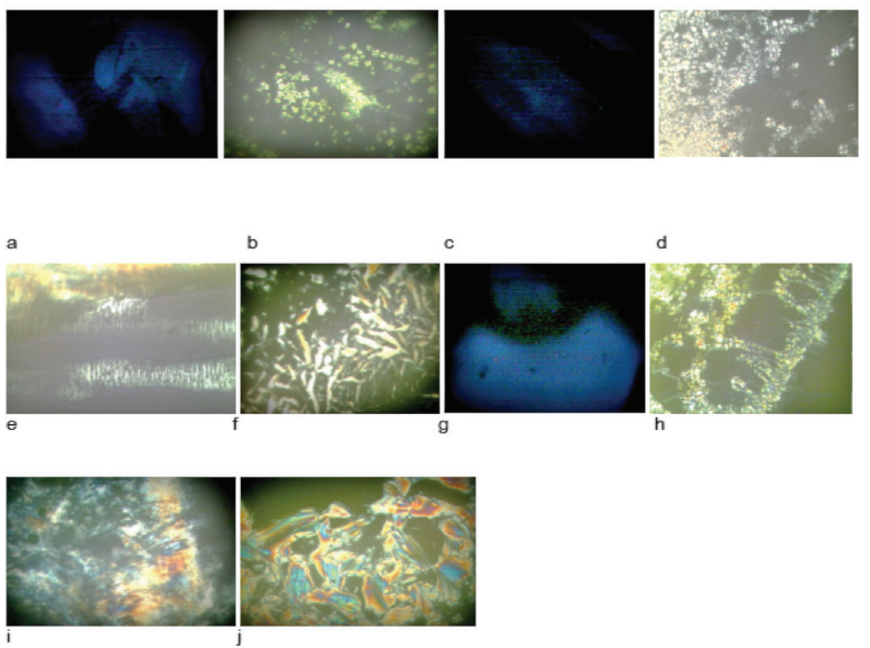

Figure 2. (a) $\mathrm{F} 1, \mathrm{~F} 6, \mathrm{~F} 3$ cubic phase at $20^{\circ} \mathrm{C}$ and $27^{\circ} \mathrm{C}$, (b) F2 cubic and lamellar phase at $20^{\circ} \mathrm{C}$, (c) F4, F5, F7, F8, F9 cubic phase at $20^{\circ} \mathrm{C}$, (d) F2 lamellar phase $27^{\circ} \mathrm{C}$, (e) F3, F8 cubic and hexagonal phase at $27^{\circ} \mathrm{C}$, (f) F4, F5, F7, F9 cubic and hexagonal phase at $27^{\circ} \mathrm{C}$, (g) F1, F6 cubic phase at 37 ${ }^{\circ} \mathrm{C}$, (h) F2 lamellar phase at $37^{\circ} \mathrm{C}$, (i) F3, F8 cubic and hexagonal phase at $37^{\circ} \mathrm{C}$, (j) F4, F5, F7, F9 cubic and hexagonal phase at $37^{\circ} \mathrm{C}$ 
Table 3. Mechanical properties and bioadhesive force of preformed gel formulations

\begin{tabular}{llllll} 
Formulation & \multicolumn{5}{l}{ Mechanical parameters $(\mathrm{n}=3)$} \\
\cline { 2 - 6 } & Hardness $(\mathrm{mN})$ & Compressibility $(\mathrm{mJ})$ & Adhesiveness $(\mathrm{mJ})$ & Cohesiveness (dimensionless) & Work of bioadhesion (mN) \\
\hline F1 & $480 \pm 40$ & $0.533 \pm 0.025$ & $1.111 \pm 0.018$ & $1.495 \pm 0.030$ & $441.29 \pm 20$ \\
\hline F2 & $313.8 \pm 30$ & $0.405 \pm 0.020$ & $0.634 \pm 0.012$ & $1.175 \pm 0.025$ & $254.97 \pm 15$ \\
\hline F3 & $333.8 \pm 20$ & $0.486 \pm 0.015$ & $0.678 \pm 0.015$ & $1.294 \pm 0.020$ & $313.81 \pm 12$ \\
\hline F4 & $1002.08 \pm 50$ & $1.452 \pm 0.022$ & $2.943 \pm 0.075$ & $1.816 \pm 0.021$ & $935.49 \pm 30$ \\
\hline F5 & $657.04 \pm 25$ & $1.256 \pm 0.025$ & $2.413 \pm 0.022$ & $1.682 \pm 0.025$ & $539.36 \pm 25$ \\
\hline F6 & $363.84 \pm 15$ & $0.824 \pm 0.015$ & $1.323 \pm 0.017$ & $1.492 \pm 0.028$ & $342.65 \pm 10$ \\
\hline F8 & $1245.44 \pm 60$ & $1.712 \pm 0.072$ & $3.143 \pm 0.12$ & $1.961 \pm 0.053$ & $1010.08 \pm 50$ \\
\hline F9 & $345.199 \pm 18$ & $0.674 \pm 0.013$ & $0.956 \pm 0.005$ & $1.323 \pm 0.025$ & $304.006 \pm 14$ \\
\hline
\end{tabular}

(Mean \pm standard deviation, $\mathrm{n}=3$ )

in adhesiveness and gel strength. Our results corroborate the reported findings. ${ }^{30}$ For formulation F2 lower values of hardness $(313.8 \pm 30 \mathrm{mN})$, compressibility $(0.445 \pm 0.020 \mathrm{~mJ})$, adhesiveness $(0.634 \pm 0.012 \mathrm{~mJ})$, cohesiveness $(1.175 \pm 0.025)$, and bioadhesion force $(254.97 \pm 15 \mathrm{mN})$ were obtained. The results for F2 showed a significant difference ( $p<0.05)$ when compared to the means of $F 7$, poor mechanical parameters were obtained due to predominant lamellar microstructuring of the gel due to high content of DMSO, and as reported lamellar phases have poor adhesion in comparison to hexagonal and cubic structures. ${ }^{31}$

\section{Rheological measurements}

Tables 4 and 5 indicate the results for the rotational and oscillatory tests, respectively. The value $n<1$ proves the system to be non-Newtonian, typically to be pseudoplastic; the oscillatory parameters complex modulus, elastic modulus, viscous modulus, and phase angle ( $\tan \delta$ ) reported are calculated at a frequency of $1 \mathrm{~Hz}$. As can be seen, the formulations where DMSO concentration was high showed lower values of consistency index, whereas with an increase in concentration of $\mathrm{OA}$ a subsequent rise in consistency index was noted. The general performance of $G^{\prime}$ and $G^{\prime \prime}$ as a function of frequency at constant strain $0.1 \%$ by the gel sample is illustrated in Figure 3. F1, F3, F4, F6, F7, and F9 typically exhibited frequency dependent moduli curves akin to a cubic mesophasic structure. Figure 4 depicts G" to be predominant at lower frequencies ( $<0.1 \mathrm{~Hz}$ not used), while $G^{\prime}$ is dominant at higher frequencies since no cross over was seen at the frequencies used in the present study. The composition of the sample plays a key role in defining the frequency at which the crossover ( $G^{\prime}>G^{\prime \prime}$ ) occurs. As the value of $G^{\prime}$ levels out after an initial increase, $G^{\prime \prime}$ is constantly reduced with increasing frequencies. All formulations indicated $G^{\prime}$ to be higher than one order of magnitude over G". The change from a primarily liquid-like behavior to a solid with increasing frequency is supplementary reflected by $\tan \delta$ values $\geq 1$ at low frequency, followed by a swift decline at the crossover, and finally reaching out at $\tan \delta$ values $\leq 0$. The curve for $F 5$ showed
Table 4. Rheological parameters of IGFPS sol and preformed gel

\begin{tabular}{llll} 
Formulation & Viscosity of sol $(\mathrm{Pa} . \mathrm{s})$ & $\mathrm{n}$ & $\mathrm{k}(\mathrm{Pa} . \mathrm{s})$ \\
\hline F1 & $0.17 \pm 0.001$ & $0.0925 \pm 0.01$ & $13.5 \pm 0.14$ \\
\hline F2 & $0.103 \pm 0.0011$ & $0.08612 \pm 0.02$ & $10.5 \pm 0.21$ \\
\hline F3 & $0.15 \pm 0.002$ & $0.09147 \pm 0.03$ & $13.1 \pm 0.25$ \\
\hline F4 & $0.449 \pm 0.015$ & $0.1467 \pm 0.005$ & $450.87 \pm 1.57$ \\
\hline F5 & $0.555 \pm 0.018$ & $0.1598 \pm 0.001$ & $571.89 \pm 1.25$ \\
\hline F6 & $0.1928 \pm 0.0012$ & $0.1102 \pm 0.032$ & $50.5 \pm 0.1$ \\
\hline F7 & $0.3899 \pm 0.002$ & $0.1246 \pm 0.004$ & $341.87 \pm 1.11$ \\
\hline F8 & $0.1684 \pm 0.0013$ & $0.09695 \pm 0.01$ & $30.2 \pm 0.5$ \\
\hline F9 & $0.3599 \pm 0.001$ & $0.099 \pm 0.012$ & $138.18 \pm 1.02$ \\
\hline
\end{tabular}

(Mean \pm standard deviation, $n=3$ ), IGFPS: In situ gelling fluid precursor systems

Table 5. Oscillatory test parameters of preformed gels at a frequency of $1 \mathrm{~Hz}$

\begin{tabular}{lllll} 
Formulation & Tan $\delta$ & $\begin{array}{l}\text { Complex } \\
\text { modulus } \\
(\mathrm{Pa}) G^{*}\end{array}$ & $\begin{array}{l}\text { Elastic } \\
\text { modulus } \\
(\mathrm{Pa}) \mathrm{G}^{\prime}\end{array}$ & $\begin{array}{l}\text { Viscous } \\
\text { modulus } \\
(\mathrm{Pa}) \mathrm{G}^{\prime \prime}\end{array}$ \\
\hline F1 & 14.69 & $5.76 \times 10^{4}$ & $6.55 \times 10^{4}$ & $1.71 \times 10^{3}$ \\
\hline F2 & 9.13 & $1.76 \times 10^{4}$ & $2.95 \times 10^{4}$ & $4.8 \times 10^{3}$ \\
\hline F3 & 11.36 & $3.12 \times 10^{4}$ & $3.06 \times 10^{4}$ & $6.13 \times 10^{3}$ \\
\hline F4 & 19.64 & $7.68 \times 10^{4}$ & $7.23 \times 10^{4}$ & $2.58 \times 10^{4}$ \\
\hline F5 & 13.91 & $1.35 \times 10^{5}$ & $1.31 \times 10^{5}$ & $3.8 \times 10^{4}$ \\
\hline F6 & 16.91 & $1.10 \times 10^{5}$ & $9.71 \times 10^{4}$ & $2.95 \times 10^{4}$ \\
\hline F7 & 17.2 & $8.3 \times 10^{4}$ & $7.96 \times 10^{4}$ & $2.47 \times 10^{4}$ \\
\hline F8 & 15.84 & $5.22 \times 10^{4}$ & $5.02 \times 10^{4}$ & $1.43 \times 10^{4}$ \\
\hline F9 & 15.9 & $7.32 \times 10^{4}$ & $7.04 \times 10^{4}$ & $2.00 \times 10^{4}$ \\
\hline
\end{tabular}

(Mean, $n=3$ )

some atypical behavior; the $\tan \delta$ values decreased with an increase in frequency, but at higher frequency the value was 
$>0$; the same has been reported elsewhere. ${ }^{32}$ It could be due to the high provenance of the HCP P63/mmc structure. G" and $G^{\prime}$ were found to increase at higher frequency and so it can be presumed that the crossover might occur at higher frequency. The sample characterized as F2 also showed a markedly different frequency dependent moduli curve quite similar to that seen for cubic to lamellar structures transformation; herein at higher frequency G" sharply shoots up and again the crossover occurs at higher frequency, thus exhibiting a viscous property at higher frequency value, although the $\tan \delta$ values were $\leq 0$.

Table 5 highlights the least complex modulus for F2, whereas F5 exhibited the highest value for complex modulus. Statistical
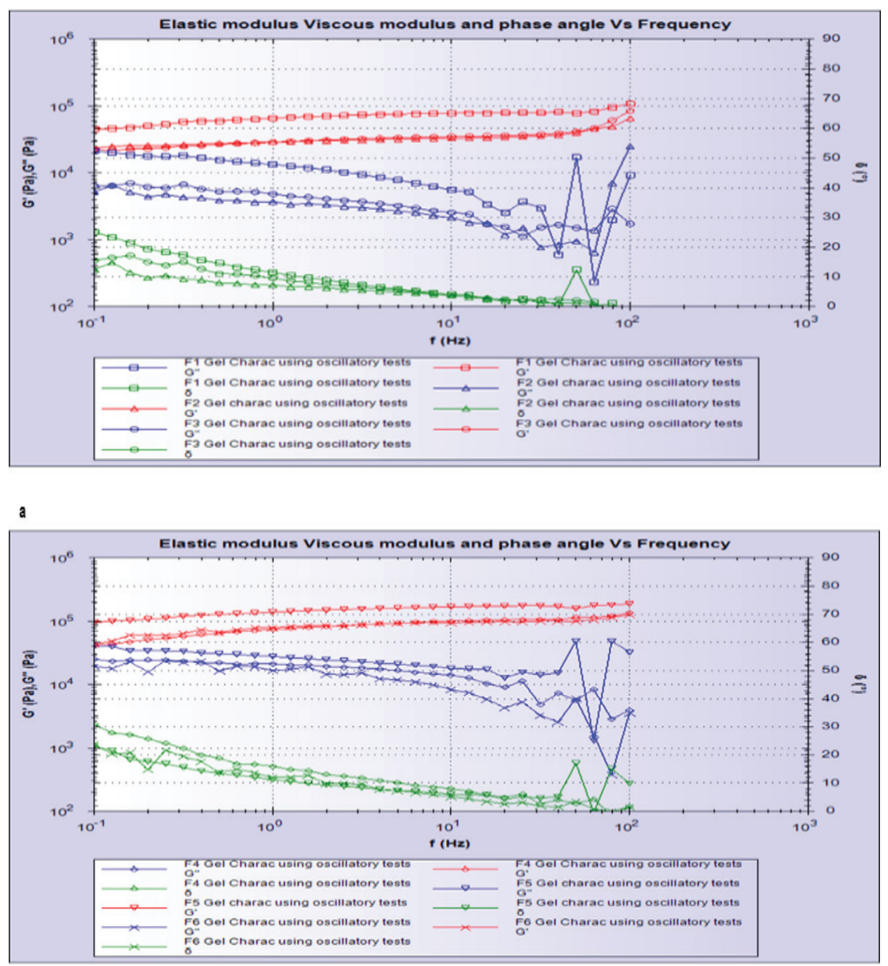

b

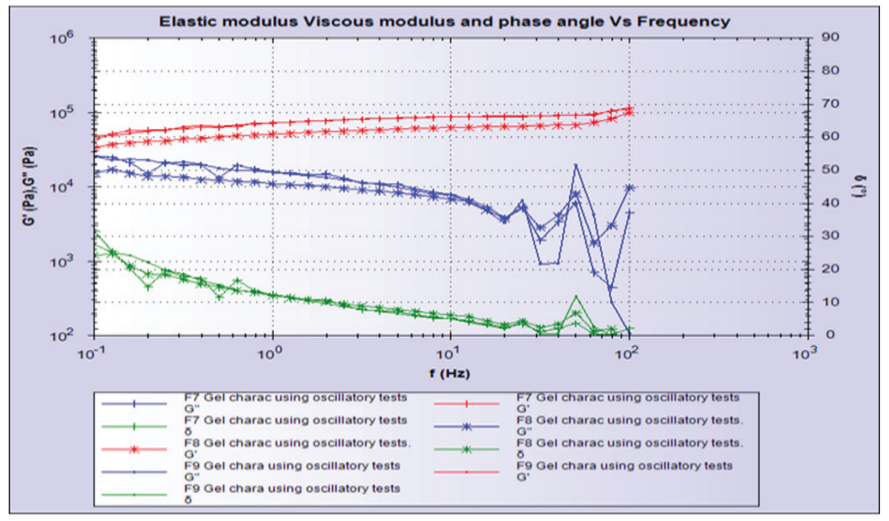

c

Figure 3. (a) Elastic modulus, viscous modulus and phase angle vs frequency for F1, F2, F3, (b) elastic modulus, viscous modulus and phase angle vs frequency for F4, F5, F6, (c) elastic modulus, viscous modulus and phase angle vs frequency for F7, F8, F9 evaluation of the oscillatory test parameters obtained at a frequency of $1 \mathrm{~Hz}$ point out no significant differences ( $p>0.05$ ) for F4 vs F7, F4 vs F9, and F7 vs F9, whereas on comparing with F5 all formulations displayed a significant difference ( $p<0.05,<0.001)$.

\section{Small angle $X$-ray scattering measurements}

The liquid crystalline gel microstructure although analyzed by PLM did not show the type of mesomorphic cubic and hexagonal structure formed. Hence, SAXS analysis of the samples becomes essential at different temperatures to affirm the type of mesomorphic structure formed on the basis of Miller indices and change in lattice parameter values. We report intriguing polycontinuous interfaces of $\mathrm{HCP} \mathrm{P} 63 / \mathrm{mmc}^{33,34}$ coexisting with $\mathrm{Im} 3 \mathrm{~m}$ at $25{ }^{\circ} \mathrm{C}$ and $37{ }^{\circ} \mathrm{C}$. Previous studies have reported the coexistence of HCP P63/mmc with Fm3m. ${ }^{35}$ The coexistence is a function of the concentration of additive and drug moiety, based on negative interfacial curvature. Studies also point to rigid and closely packed mixed films of phospholipid with nystatin. ${ }^{36}$ It has been previously reported that DMSO expands the $1 \mathrm{~m} 3 \mathrm{~m} / \mathrm{Pn} 3 \mathrm{~m}$ cubic phase coexistence region in the phase diagram and increases the lattice constant of the Pn3m monoolein cubic phase. ${ }^{26}$ Our results were in contrast to the obtained finding; the presence of $\mathrm{OA}$ and nystatin could be the reason for this, although an increase in lattice constant value is seen for $\operatorname{Im} 3 \mathrm{~m}$ cubic phase with an increase in DMSO concentration. SAXS analysis was performed on all the gel formulations and diffractograms were taken at various temperatures, i.e. $20{ }^{\circ} \mathrm{C}, 25^{\circ} \mathrm{C}$, and $37^{\circ} \mathrm{C}$, to ascertain the effect of temperature on phase transformation and change in lattice parameter. Figure 4 indicates the SAXS diffractograms for all formulations at $20^{\circ} \mathrm{C}$; it was seen that all gel samples except for F2 exhibited $\operatorname{Im} 3 m$ ( $\sqrt{2}: \sqrt{ } 4: \sqrt{ } 6: \sqrt{ } 8: \sqrt{ } 10: \sqrt{ } 12: \sqrt{ } 14)$, a primitive type of cubic phase structure characterized by three interpenetrating continuous networks, whereas for F2 Im $3 \mathrm{~m}$ phase coexisted with lamellar phase lamellar ( $L \alpha)$ $(\sqrt{ } 1: \sqrt{ } 4: \sqrt{ } 9: \sqrt{ } 16)$. On cooling self-assembled lipid structures at lower temperature, reduction of bilayer curvature occurs, which causes an increase in lattice parameter. ${ }^{37,38}$ The SAXS diffractogram at $25^{\circ} \mathrm{C}$ is shown in Figure 5 , which indicates that they are sensitive to change in temperature; F2 was seen to stand apart from the rest with distinctive lamellar peak ratios; and $\mathrm{F} 1$ and $\mathrm{F} 6$ demonstrate the presence of only $1 \mathrm{~m} 3 \mathrm{~m}$ phase, whereas the others indicate coexistence of $1 \mathrm{~m} 3 \mathrm{~m}$ with P63/ $m m c(\sqrt{ } 4: \sqrt{ } 16: \sqrt{ } 1: \sqrt{ } 2: \sqrt{ } 5)$. Complete phase transformation for F2 is seen at $25^{\circ} \mathrm{C}$, as the bilayers lack excess area in the form of thermal undulations and less lateral tension in the bilayers leads to complete transformation to lamellar phase. The SAXS diffractogram at $37{ }^{\circ} \mathrm{C}$ indicates a decline in lattice parameter due to shrinking of the water channels with retention in the mesophasic structure (Table 6). The findings relate to DMSO's unique ability to act both as a kosmotrope (water-structure maker) and chaotrope (water structure breaker) based on its concentration. Finally, the obtained PLM images for all gel samples at respective temperature are in good agreement with the SAXS diffractograms. 


\section{Differential scanning calorimeter}

DSC studies are used in surfactant based microstructures to identify different types and states of water ${ }^{39,40}$ The phase structure in a surfactant system and interaction among polar moieties and water molecule can be identified briefly through understanding the state of water in the microstructure by subjecting samples to subzero temperature DSC scanning.
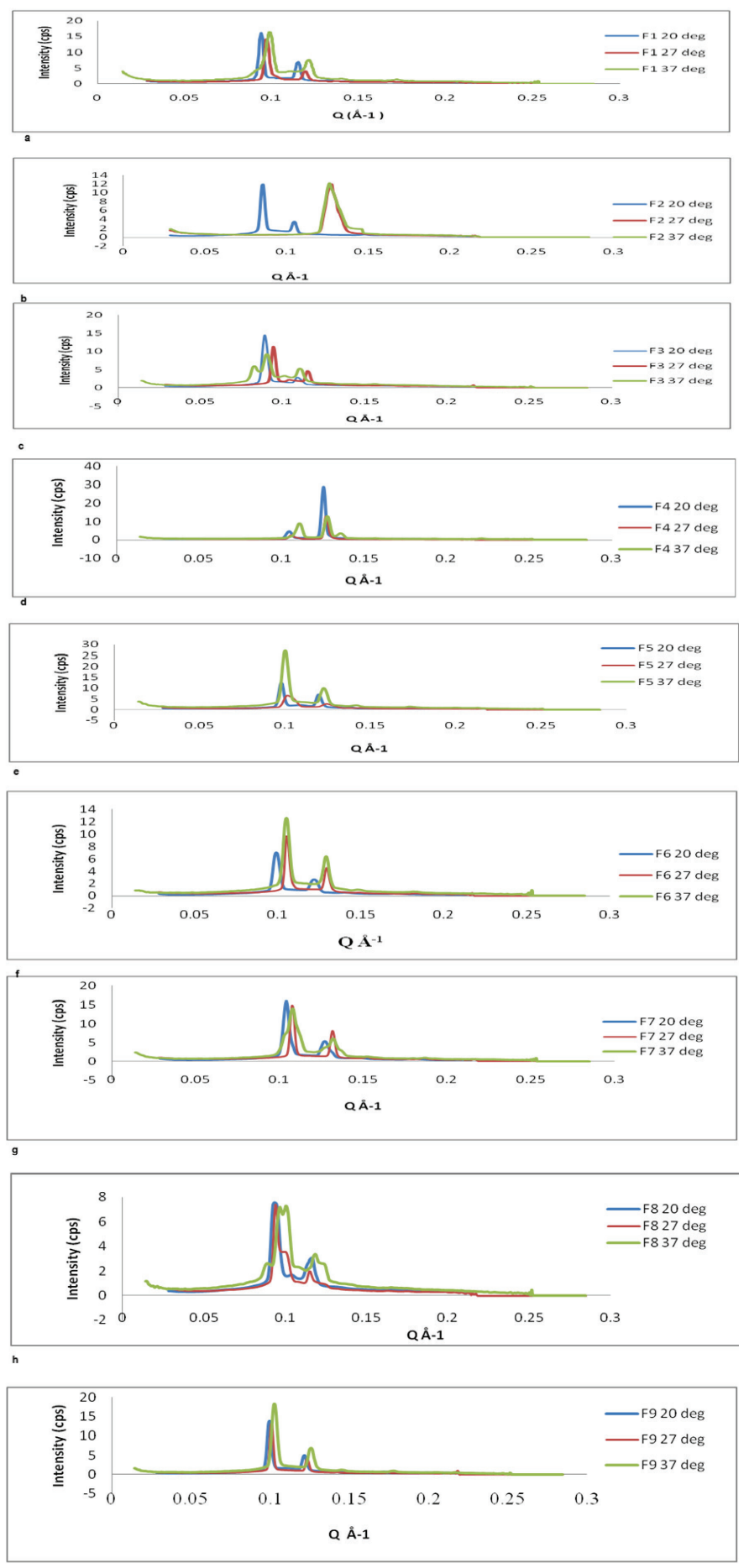

Figure 4. SAXS profile of preformed gel samples at $20^{\circ} \mathrm{C}, 27^{\circ} \mathrm{C}$, and $37^{\circ} \mathrm{C}$ (a) F1, (b) F2, (c) F3, (d) F4, (e) F5, (f) F6, (g) F7, (h) F8, (i) F9

SAXS: Small angle $X$-ray scattering
Table 7 and Figure 5 depict a sharp depression in the freezing point of free water characterized by an exothermic peak corresponding to crystallization of ice and two endothermic peaks. The first endothermic peak corresponds to melting for GMO/OA/DMSO interactions, whereas the second peak at low temperature indicates melting of interfacial water/bounded water. The interfacial water corresponds to the water entrapped in the highly ordered mesophasic structures. An endothermic peak for free water was not seen for any formulation but one was noted and is ascribed to crystallization of the ice formation in DMSO/water solvent mixture out of the inter-membrane space in the bulk solvent. Minimal changes in endothermic peak temperature were seen for interfacial water in gel samples. The data indicate that the exothermic peak temperature was dependent on DMSO concentration in the gel system and thus $\mathrm{F} 2$ indicated high depression in the freezing temperature for crystallization of ice in the binary mixture of DMSO and water. It is reported that at low concentration DMSO is strongly bonded to two water molecules and thus rigidifies the water structure, whereas at higher concentration it breaks the water structure and this is strongly evident by a decrease in the coordination number of water, which leads to a more distorted tetrahedral structure. 39,40 Exothermic peak temperatures obtained for formulations F4, F5, and F7 are in corroboration with the above statement. In agreement with the SAXS data, the DSC results also show DMSO's ability to work as either a kosmotropic or chaotropic solvent depending on its concentration. At low concentration it works as a water structure maker, whereas at high concentration it breaks the water structure and this is explained by a change in the exothermic peak temperature of free water in various gel formulations. The results obtained for DSC studies are in line with the minimum volume of solvent required for gelation.

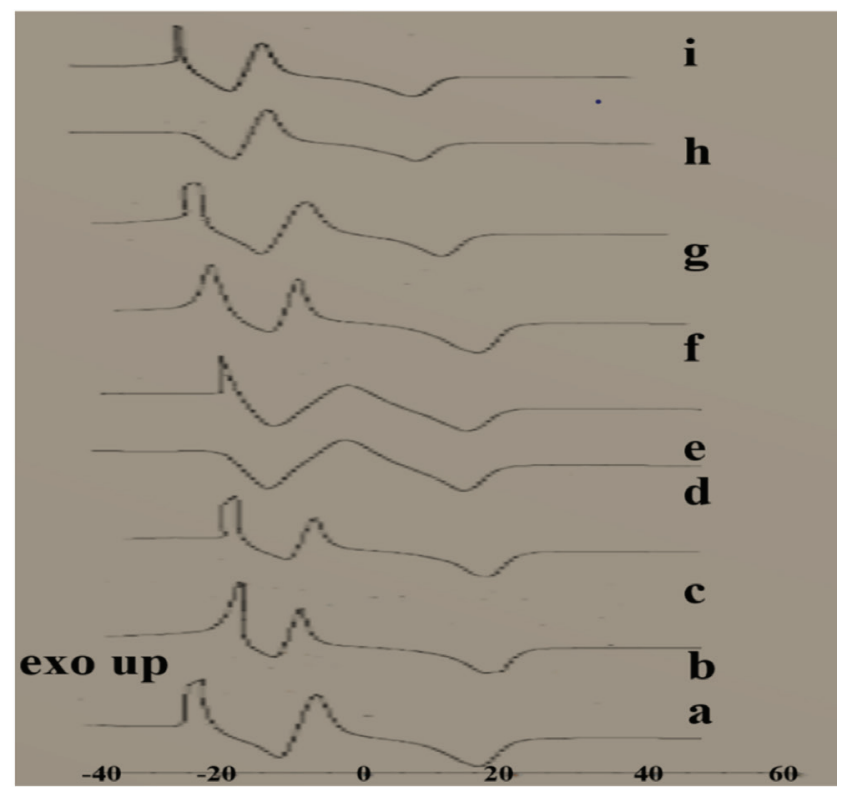

Figure 5. DSC thermograms of preformed gel samples (a) F1, (b) F2, (c) F3, (d) F4, (e) F5, (f) F6, (g) F7, (h) F8, (i) F9

DSC: Differential scanning calorimeter 
Table 6. Lattice parameter, microstructure and lattice ratio of preformed gel samples at $20^{\circ} \mathrm{C}, 27^{\circ} \mathrm{C}$, and $37^{\circ} \mathrm{C}$

\begin{tabular}{|c|c|c|c|c|c|c|c|c|c|}
\hline Temp. & $20^{\circ} \mathrm{C}$ & & & $27^{\circ} \mathrm{C}$ & & & $37^{\circ} \mathrm{C}$ & & \\
\hline Gel & $\alpha(\AA)$ & Lattice ratio & Structure & $\alpha(\AA)$ & Lattice ratio & Structure & $\alpha(\AA)$ & $\begin{array}{l}\text { Lattice } \\
\text { ratio }\end{array}$ & Structure \\
\hline F1 & $94.28 \pm 0.611$ & - & $\operatorname{lm} 3 \mathrm{~m}, \mathrm{Q}^{229}$ & $91.32 \pm 0.39$ & - & $\operatorname{lm} 3 \mathrm{~m}, \mathrm{Q}^{229}$ & $91.32 \pm 0.85$ & - & $\begin{array}{l}\operatorname{lm} 3 m \\
Q^{229}\end{array}$ \\
\hline $\mathrm{F} 2$ & $\begin{array}{l}157.85 \pm 0.086 \\
104.53\end{array}$ & 1.509 & $\begin{array}{l}\text { Lamellae, L } \alpha \\
\operatorname{Im} 3 \mathrm{~m}, \mathrm{Q}^{229}\end{array}$ & $150.43 \pm 0.825$ & - & $\begin{array}{l}\text { Lamellae } \\
\text { L } \alpha\end{array}$ & $144.43 \pm 0.83$ & - & $\begin{array}{l}\text { Lamellae } \\
\text { L } \alpha\end{array}$ \\
\hline F3 & $99.54 \pm 0.889$ & - & Im3m, Q Q 229 & $\begin{array}{l}98.19 \pm 0.687 \\
84.3 \pm 0.513\end{array}$ & 1.164 & $\begin{array}{l}\text { Im3m, Q } 229 \\
\mathrm{HCP}(\mathrm{P} 63 / \mathrm{mmc})\end{array}$ & $\begin{array}{l}94.18 \pm 0.57 \\
81.64 \pm 0.826\end{array}$ & 1.15 & $\begin{array}{l}\operatorname{lm} 3 \mathrm{~m}, \mathrm{Q}^{229} \\
\mathrm{HCP}(\mathrm{P} 63 / \mathrm{mmc})\end{array}$ \\
\hline F4 & $84.99 \pm 1.15$ & - & $\operatorname{Im} 3 \mathrm{~m}, \mathrm{Q}^{229}$ & $\begin{array}{l}83.33 \pm 0.577 \\
64.75 \pm 0.507\end{array}$ & 1.28 & $\begin{array}{l}\text { Im3m, } Q^{229} \\
\operatorname{HCP}(P 63 / m m c)\end{array}$ & $\begin{array}{l}80.274 \pm 0.72 \\
64.33 \pm 0.69\end{array}$ & 1.24 & $\begin{array}{l}\operatorname{lm} 3 \mathrm{~m}, \mathrm{Q}^{229} \\
\mathrm{HCP}(\mathrm{P} 63 / \mathrm{mmc})\end{array}$ \\
\hline F5 & $89.03 \pm 1$ & - & $\operatorname{lm} 3 \mathrm{~m}, \mathrm{Q}^{229}$ & $\begin{array}{l}88.86 \pm 1.037 \\
67.35 \pm 0.7\end{array}$ & 1.319 & $\begin{array}{l}\operatorname{lm} 3 m \\
Q^{229} \\
\mathrm{HCP}(\mathrm{P} 63 / \mathrm{mmc})\end{array}$ & $\begin{array}{l}80.52 \pm 1.26 \\
62.13 \pm 0.618\end{array}$ & 1.295 & $\begin{array}{l}\operatorname{lm} 3 \mathrm{~m}, \mathrm{Q}^{229} \\
\mathrm{HCP}(\mathrm{P} 63 / \mathrm{mmc})\end{array}$ \\
\hline F6 & $88.06 \pm 0.970$ & - & $\operatorname{lm} 3 \mathrm{~m}, \mathrm{Q}^{229}$ & $84 \pm 0.577$ & - & $\operatorname{lm} 3 \mathrm{~m}, \mathrm{Q}^{229}$ & $84.6 \pm 0.923$ & - & $\operatorname{lm} 3 \mathrm{~m}, \mathrm{Q}^{229}$ \\
\hline $\mathrm{F} 7$ & $84.9 \pm 0.802$ & - & $\operatorname{lm} 3 \mathrm{~m}, \mathrm{Q}^{229}$ & $\begin{array}{l}82.57 \pm 0.906 \\
66.02 \pm 0.59\end{array}$ & 1.25 & $\begin{array}{l}\text { Im3m, } Q^{229} \\
\operatorname{HCP}(P 63 / m m c)\end{array}$ & $\begin{array}{l}79.11 \pm 1.06 \\
64.14 \pm 0.621\end{array}$ & 1.23 & $\begin{array}{l}\operatorname{Im} 3 \mathrm{~m}, \mathrm{Q}^{299} \\
\mathrm{HCP}(\mathrm{P} 63 / \mathrm{mmc})\end{array}$ \\
\hline F8 & $93.23 \pm 0.577$ & - & $\operatorname{lm} 3 \mathrm{~m}, \mathrm{Q}^{229}$ & $\begin{array}{l}92.67 \pm 0.964 \\
82.07 \pm 0.558\end{array}$ & 1.12 & $\begin{array}{l}\text { Im3m, Q229 } \\
\text { HCP (P63/mmc) }\end{array}$ & $\begin{array}{l}89.4 \pm 0.635 \\
80.6 \pm 0.808\end{array}$ & 1.109 & $\begin{array}{l}\operatorname{lm} 3 \mathrm{~m}, \mathrm{Q}^{229} \\
\mathrm{HCP}(\mathrm{P} 63 / \mathrm{mmc})\end{array}$ \\
\hline F9 & $88.21 \pm 0.512$ & - & $\operatorname{Im} 3 \mathrm{~m}, \mathrm{Q}^{229}$ & $\begin{array}{l}87 \pm 0.577 \\
70.16 \pm 0.628\end{array}$ & 1.24 & $\begin{array}{l}\operatorname{Im} 3 m, Q^{229} \\
\operatorname{HCP}(P 63 / m m c)\end{array}$ & $\begin{array}{l}83 \pm 0.57 \\
68.57 \pm 0.794\end{array}$ & 1.211 & $\begin{array}{l}\operatorname{lm} 3 m, Q^{229} \\
\operatorname{HCP}(P 63 / m m c)\end{array}$ \\
\hline
\end{tabular}

(Mean \pm standard deviation, $n=3$ ), HCP: Hexagonal phase, L $\alpha$ : Lamellar, Temp: Temperature

Table 7. Endothermic and exothermic events their peak temperature and enthalpy of preformed gel samples

\begin{tabular}{|c|c|c|c|c|c|c|}
\hline Formulation & \multicolumn{2}{|c|}{ Endothermic peak temperature $\left({ }^{\circ} \mathrm{C}\right)$} & \multicolumn{2}{|c|}{ Enthalpy (W/g) for endothermic peaks } & $\begin{array}{l}\text { Exothermic peak } \\
\text { temperature }\left({ }^{\circ} \mathrm{C}\right) \\
\text { Free water }\end{array}$ & $\begin{array}{l}\text { Enthalpy }(\mathrm{W} / \mathrm{g}) \text { for } \\
\text { exothermic peak } \\
\text { Free water }\end{array}$ \\
\hline $\mathrm{F} 2$ & -16.55 & 12.83 & -0.7723 & -1.36 & -12.88 & 0.9938 \\
\hline F3 & -15.37 & 14.73 & -0.7966 & -1.46 & -10.86 & 0.8696 \\
\hline F5 & -16.08 & 11.41 & -0.9168 & -1.052 & -5.05 & 0.2587 \\
\hline F6 & -15.84 & 15.68 & -0.6651 & -1.276 & -11.09 & 0.9765 \\
\hline $\mathrm{F} 7$ & -13.94 & 12.83 & -1.253 & -1.327 & -6.35 & 0.8252 \\
\hline
\end{tabular}

\section{In vitro drug release rate}

The release profiles of a water-insoluble drug, nystatin, from preformed mesophasic gel formulations were studied to understand the effect of various factors such as addition of components to liquid crystalline phases, lattice parameter, and the rate of swelling. ${ }^{24}$ The results obtained corroborate with such findings as depicted in Figure 6. F2 exhibited the maximum rate of swelling, showing rapid release of drug, i.e. $94 \%$ at 8 h. Higher concentrations of DMSO in F2 work as a cosolvent in solubilization of nystatin and the head groups are better hydrated, thereby forming larger water channels; this is ascertained by the higher lattice parameter value of 144.43 . The

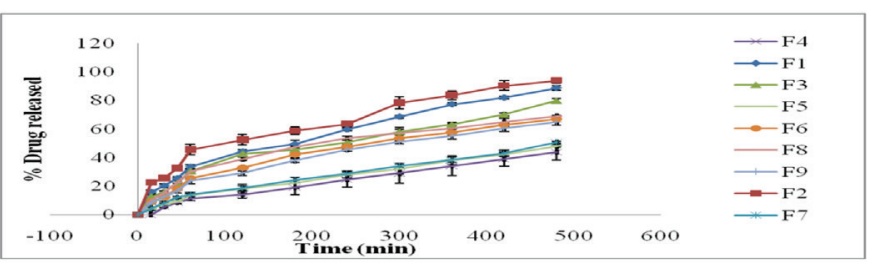

Figure 6. \% Drug released vs time profile of gelled samples

assessment for F5 indicates a lower rate of swelling and thus a lower drug release of $48 \%$ at the end of $8 \mathrm{~h}$. In agreement with previous findings, ${ }^{41,42}$ the following reason may be alluded to in order to understand the observed behavior: nystatin, although 
Table 8. Drug release kinetics of the gelled samples

Formulation $\quad \mathrm{R}^{2}$ value

Best fit Parameters for Korsemeyer

model Peppas equation

Zero order First order Matrix Peppas Hixson Crowell

Zero order First order Matrix Peppas Hixson Crowell

\begin{tabular}{lllllllll}
\hline F1 & 0.9295 & 0.5151 & 0.9929 & 0.9898 & 0.9585 & Matrix & 3.0918 & 0.52103 \\
\hline F2 & 0.9031 & 0.4295 & 0.9871 & 0.9174 & 0.9761 & Matrix & 6.4823 & 0.4572 \\
\hline F3 & 0.9445 & 0.5039 & 0.9984 & 0.9975 & 0.9797 & Martix & 3.8208 & 0.5069 \\
\hline F4 & 0.9802 & 0.6651 & 0.9784 & 0.9971 & 0.9873 & Peppas & 1.1058 & 0.6255 \\
\hline F5 & 0.9798 & 0.6971 & 0.9852 & 0.9928 & 0.9891 & Peppas & 0.6921 & 0.6691 \\
\hline F6 & 0.9327 & 0.5629 & 0.9933 & 0.9912 & 0.9444 & Matrix & 2.7079 & 0.5063 \\
\hline F7 & 0.9783 & 0.6681 & 0.9791 & 0.9951 & 0.9862 & Peppas & 1.1009 & 0.6391 \\
\hline F8 & 0.8666 & 0.5029 & 0.9781 & 0.9746 & 0.9333 & Matrix & 3.2506 & 0.4752 \\
\hline
\end{tabular}

solubilized, is localized at the lipid/water interface, and the partitioning into the continuous hydrophobic phase (formed by GMO and $\mathrm{OA}$ ) and aqueous channels becomes the rate limiting step for drug release. In addition, investigating SAXS analyses for F5 confirms a bicontinuous cubic phase ( $\mathrm{Im} 3 \mathrm{~m})$ with an interstice of inverted HCP (P63/mmc) structure. For $\mathrm{F} 5$ the lattice parameter ratio of $1 \mathrm{~m} 3 \mathrm{~m} / \mathrm{HCP}(\mathrm{P} 63 / \mathrm{mmc})$ at $37^{\circ} \mathrm{C}$ also governed the drug release pattern. $\mathrm{F} 5$ exhibited a ratio of 1.295, whereas F4 and F7 displayed a ratio of 1.24 and 1.23 , respectively. Thus, it can be concluded that an inverse relationship exists between the lattice parameter ratio and drug release; as the ratio increases the drug release decreases. The statistical evaluation revealed an insignificant difference among F4, F5, and F7 ( $p>0.05$, >0.999), whereas a significant difference was noted on comparing means of F4, F5, and F7 against means of F2 ( $p<0.05,<0.03)$. This clarifies the effect of DMSO as a solubilizing cosolvent at high concentration and its role in modulating microstructure, thus controlling the release of drug.

The drug release data were subjected to kinetic modeling and the results are presented in Table 8 . It is revealed that all formulations showed a matrix type of release pattern except for F4, F5, and F7, which indicated the Peppas model of release pattern. This identifies that LLC phases do not follow simple diffusion or erosion, and a thus anomalous $(0.45<n<0.89)$ mechanism is involved.

\section{In vitro antifungal activity}

The in vitro antifungal activity of the formulated IFGPS was evaluated to ascertain its efficacy against Aspergillus fumigatus and Candida albicans. In vitro antifungal activity was also tested to substantiate the in vitro drug releasing ability of gel formulations. Figure 7 shows the zone of inhibition $(\mathrm{mm})$ for IFGPS and standard nystatin drug solution. Concentration of DMSO played a crucial role in controlling in vitro antifungal activity; IFGPS F2 exhibited a zone of inhibition of $18 \mathrm{~mm}$ and $17 \mathrm{~mm}$ against Candida albicans and Aspergillus fumigatus, respectively. The standard drug solution in DMSO was used

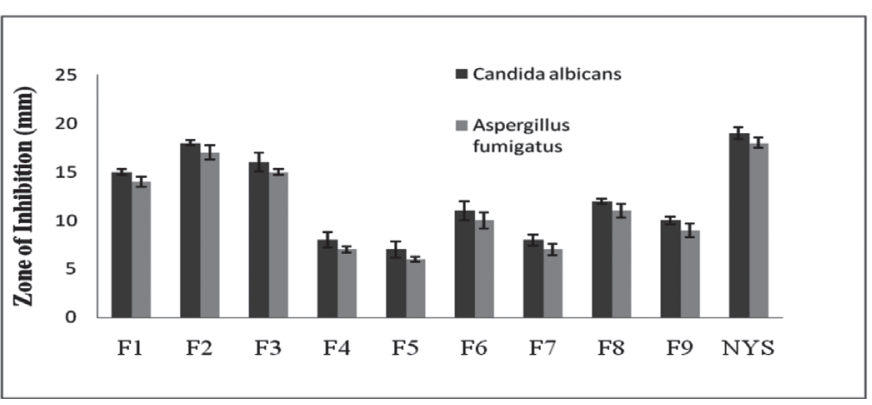

Figure 7. Zone of inhibition of gel samples obtained against Aspergillus fumigatus and Candida albicans

as a control to compare against the formulated IFGPS. In comparison to the standard drug solution, formulation F2 showed no significant difference ( $p>0.05,0.3546)$, whereas for all the other IFGPS a significant difference ( $p<0.0001)$ was seen. OA has a mitigating role in the release of nystatin. An increase in its concentration led to a decrease in the zone of inhibition and this could be due to higher partitioning of the drug into the oil phase and being retained either at the oil/ water interface or being bonded to the lipophilic groups of GMO or $\mathrm{OA}$, thus being unable to be released from the matrix. On comparing formulations F4, F5, and F7 against the mean values of $F 2$ a significant difference ( $p<0.0001)$ was noted, whereas on comparing the mean of F4, F5, and F7 amongst each other no significant difference ( $p>0.05,0.1229,>0.99$ ) was obtained. The results are in agreement with the data obtained for in vitro drug release. Moreover, the matrices of formulation F5, F4, and F7 did reveal an increase in the zone of inhibition on examination after $48 \mathrm{~h}$ in a range of $2 \pm 0.08 \mathrm{~mm}$, and thus are shown to be sustained release matrices.

\section{CONCLUSION}

The results of the present work revealed that IGFPS containing GMO/OA/DMSO could be used for sustaining the release of a polyene antifungal agent, nystatin. The impact of incorporating a polar aprotic solvent had a divergent effect on modulation 
of the gel microstructure, which ultimately improved the performance magnitude of the delivery system. The IGFPS formed various mesophasic structures like $L \alpha$ and bicontinuous cubic Im3m, and coexistence of Im3m with hexagonal HCP P63/ mmc was affirmed by SAXS and polarized optical microscopy. DSC and SAXS studies highlight DMSO's ability to work either as a kosmotropic or chaotropic solvent, being a function of its concentration. Rheological and oscillatory assessments confirmed all samples show shear thinning behavior, and the gels show frequency dependent rheograms of entirely elastic nature $\left.G^{\prime}\right\rangle G^{\prime \prime}$. Texture analysis results underline the presence of requisite mechanical and mucoadhesive properties.

Finally, an in vitro antifungal activity and an in vitro drug release kinetic study proved that in F7 IGFPS containing nystatin has the suitable controlled release property required for an effective mucoadhesive sustain release delivery system. In vivo and stability studies are essential to substantiate the obtained findings, and the model needs to be studied for specific route of administration.

\section{ACKNOWLEDGEMENTS}

The authors are thankful to Glenmark Pharmaceuticals, India, for providing nystatin as gift sample, and Croda, India for giving Cithrol GMO HP-SO-(LK). We are highly obliged to Malveran, India, for offering technical support for the oscillatory analysis.

Conflicts of interest: No conflict of interest was declared by the authors. The authors alone are responsible for the content and writing of the paper.

\section{REFERENCES}

1. Kligman AM. Topical pharmacology and toxicology of dimethyl sulfoxide. JAMA. 1965;193:796-804.

2. Vignes R. Dimethyl sulfoxide (DMSO), A "new” clean, unique, superior solvent. Annual Meeting. Washington, DC.; 2000.

3. Yu ZW, Quinn PJ. The effect of dimethyl sulphoxide on the structure and phase behaviour of palmitoleoylphosphatidylethanolamine. Biochim Biophys Acta. 2000;1509:440-450.

4. de Menorval MA, Mir LM, Fernandez ML, Reigada R. Effects of dimethyl sulfoxide in cholesterol-containing lipid membranes: a comparative study of experiments in silico and with cells. PloS One. 2012;7:e41733.

5. Milak S, Zimmer A. Glycerol monooleate liquid crystalline phases used in drug delivery systems. Int J Pharm. 2015:478:569-587.

6. Ng AW, Wasan KM, Lopez-Berestein G. Development of liposomal polyene antibiotics: an historical perspective. J Pharm Sci. 2003;6:6783.

7. Chen Y, Liang X, Ma P, Tao Y, Wu X, Wu X, Chu X, Gui S. Phytantriolbased in situ liquid crystals with long-term release for intra-articular administration. AAPS PharmSciTech. 2015;16:846-854.

8. Dehghan MHG, Marzuka M. Lyophilized Chitosan/xanthan Polyelectrolyte Complex Based Mucoadhesive Inserts for Nasal Delivery of Promethazine Hydrochloride. Iran J Pharm Res. 2014;13:769-784.

9. Schott $\mathrm{H}$. Kinetics of swelling of polymers and their gels. J Pharm Sci. 1992;81:467-470.
10. Souza C, Watanabe E, Borgheti-Cardoso LN, De Abreu Fantini MC, Lara MG. Mucoadhesive system formed by liquid crystals for buccal administration of poly(hexamethylene biguanide) hydrochloride. J Pharm Sci. 2014;103:3914-3923.

11. Lee J, Choi SU, Yoon MK, Choi YW. Kinetic characterization of swelling of liquid crystalline phases of glyceryl monooleate. Arc Pharm Res. 2003;26:880-885.

12. Rosevear FB. The microscopy of the liquid crystalline neat and middle phases of soaps and synthetic detergents. J Am Oil Chem Soc. 1954;31:628-639.

13. Mitchell BM, Wu TG, Jackson BE, Wilhelmus KR. Candida albicans strain-dependent virulence and Rim13p-mediated filamentation in experimental keratomycosis. Invest Ophthalmol Visl Sci. 2007;48:774780.

14. Petrikkou E, Rodriguez-Tudela JL, Cuenca-Estrella M, Gomez A, Molleja A, Mellado E. Inoculum standardization for antifungal susceptibility testing of filamentous fungi pathogenic for humans. J Clin Microbiol. 2001;39:1345-1347.

15. Fernandez-Campos F, Naveros BC, Lopez Serrano O, Alonso Merino C, Campmany ACC. Evaluation of novel nystatin nanoemulsion for skin candidosis infections. Mycoses. 2013;56:70-81.

16. Fong WK, Hanley T, Boyd BJ. Stimuli responsive liquid crystals provide 'on-demand' drug delivery in vitro and in vivo. J Control Release. 2009;135:218-226.

17. Kwon TK, Kim JC. Monoolein cubic phase containing acidic proteinoid: pH-dependent release. Drug Dev Ind Pharm. 2011;37:56-61.

18. Negrini R, Mezzenga R. pH-responsive lyotropic liquid crystals for controlled drug delivery. Langmuir. 2011;27:5296-5303.

19. de Campo L, Yaghmur A, Sagalowicz L, Leser ME, Watzke H, Glatter 0 . Reversible phase transitions in emulsified nanostructured lipid systems. Langmuir. 2004;20:5254-5261.

20. Cowie JMG, Toporowski PM. Association in the binary liquid system dimethyl sulphoxide-water. Can J Chem. 1961;39:2240-2243.

21. Ur-Rehman T, Tavelin S, Gröbner G. Effect of DMSO on micellization, gelation and drug release profile of Poloxamer 407. Int J Pharm. 2010;394:92-98.

22. Watase MNK. Effects of $\mathrm{pH}$ and DMSO content on the thermal and rheological properties of high methoxyl pectin-water gels. Carbohydrate Polymers. 1993;20:175-181.

23. Lara MG, Bentley MVLB, Collett JH. In vitro drug release mechanism and drug loading studies of cubic phase gels. Int J Pharm. 2005;293:241250.

24. Rizwan SB, Hanley T, Boyd BJ, Rades T, Hook S. Liquid crystalline systems of phytantriol and glyceryl monooleate containing a hydrophilic protein: Characterisation, swelling and release kinetics. J Pharm Sci. 2009;98:4191-4204.

25. Chang $\mathrm{CM}$, Bodmeier R. Swelling of and drug release from monoglyceride-based drug delivery systems. J Pharm Sci. 1997;86:747752.

26. Abe S, Takahashi H. A comparative study of the effects of dimethylsulfoxide and glycerol on the bicontinuous cubic structure of hydrated monoolein and its phase behavior. Chem Phys Lipids. 2007;147:59-68.

27. Conn CE, Ces O, Mulet X, Finet S, Winter R, Seddon JM, Templer $\mathrm{RH}$. Dynamics of structural transformations between lamellar 
and inverse bicontinuous cubic lyotropic phases. Phys Rev Lett. 2006;96:108102.

28. Mulet X, Boyd BJ, Drummond CJ. Advances in drug delivery and medical imaging using colloidal lyotropic liquid crystalline dispersions. J Colloid Interface Sci. 2013;393:1-20.

29. Hartnett TE, Ladewig K, O'Connor AJ, Hartley PG, McLean KM. Size and Phase Control of Cubic Lyotropic Liquid Crystal Nanoparticles. J Phys Chem B. 2014;118:7430-7439.

30. Oyafuso MH, Carvalho FC, Takeshita TM, De Souza ALR, Araujo DR, Merino V, Gremiao MPD, Chorilli M. Development and In Vitro Evaluation of Lyotropic Liquid Crystals for the Controlled Release of Dexamethasone. Polymers (Basel). 2017;9:330.

31. Evenbratt $\mathrm{H}, \mathrm{Ström} A$. Phase behavior, rheology, and release from liquid crystalline phases containing combinations of glycerol monooleate, glyceryl monooleyl ether, propylene glycol, and water. RSC Advances. 2017;7:32966-32973.

32. Schröder-Turk GE, Varslot T, de Campo L, Kapfer SC, Mickel W. A Bicontinuous Mesophase Geometry with Hexagonal Symmetry. Langmuir. 2011;27:10475-10483.

33. Shearman GC, Tyler Al, Brooks NJ, Templer RH, Ces O, Law RV, Seddon JM. A 3-D hexagonal inverse micellar lyotropic phase. J Am Chem Soc. 2009;131:1678-1679.

34. Soni SS, Brotons G, Bellour M, Narayanan T, Gibaud A. Quantitative SAXS analysis of the P123/water/ethanol ternary phase diagram. J Phys Chem B. 2006;110:15157-15165.

35. Chen Z, Jiang Y, Dunphy DR, Adams DP, Hodges C, Liu N, Zhang N, Xomeritakis G, Jin X, Aluru NR, Gaik SJ, Hilhouse HW, Brinker CJ.
DNA translocation through an array of kinked nanopores. Nat Mater. 2010;9:667-675.

36. Hac-Wydro K, Dynarowicz-Latka P. Interaction between nystatin and natural membrane lipids in Langmuir monolayers--the role of a phospholipid in the mechanism of polyenes mode of action. Biophys Chem. 2006;123:154-161.

37. Borné J, Nylander T, Khan A. Phase Behavior and Aggregate Formation for the Aqueous Monoolein System Mixed with Sodium Oleate and Oleic Acid. ACS Publications Most Trusted Most Cited Most Read. 2001;17:7742-7751.

38. Gurfinkel J, Aserin A, Garti N. Interactions of surfactants in nonionic/ anionic reverse hexagonal mesophases and solubilization of $\alpha$-chymotrypsinogen A. Colloids and Surfaces A Physicochemical and Engineering Aspects. 2011;392:322-328.

39. Shashkov SN, Kiselev MA, Tioutiounnikov SN, Kiselev AM, Lesieur P. The study of DMSO/water and DPPC/DMSO/water system by means of the X-Ray, neutron small-angle scattering, calorimetry and IR spectroscopy. Physica B: Condensed Matter. 1999;271:184-191.

40. Yaghmur A, Weng LS. In situ forming drug delivery systems based on lyotropic liquid crystalline phases : structural characterization and release properties. J Drug Deliv Sci Technol. 2013;23:325-332.

41. Mei L, Huang X, Xie Y, Chen J, Huang Y, Wang B, Wang H, Pan X, Wu C. An injectable in situ gel with cubic and hexagonal nanostructures for local treatment of chronic periodontitis. Drug Deliv. 2017;24:1148-1158.

42. Patil SS, Venugopal E, Bhat S, Mahadik KR, Paradkar AR. Exploring Microstructural Changes in Structural Analogues of IbuprofenHosted In Situ Gelling System and Its Influence on Pharmaceutical Performance. AAPS PharmSci Tech. 2015;16:1153-1159. 